\title{
Basic principles of nuclear techniques and applications in livestock production
}

P.I.Rekwot, VO.Sekoni, IS.P.Mallam, E,K,Bawa, Y.UAbubakar and C.B.IAlawa Artificial insemination thit Nationgl Animal Production Research Instipate, Shika "Ahmadu Bello

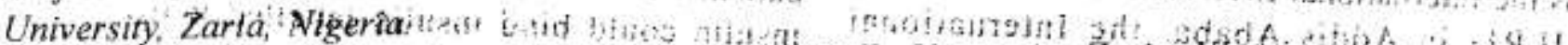
'Centre for Energy, Reféarchand Fraining, Ahmadu Bello Lniversitg Zaria, Nigerid.

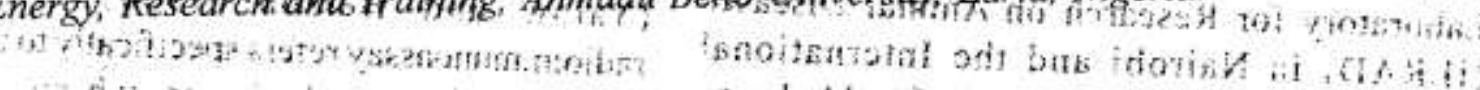

Abstract

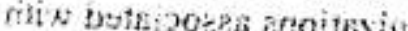

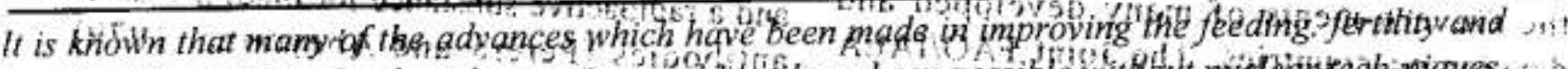

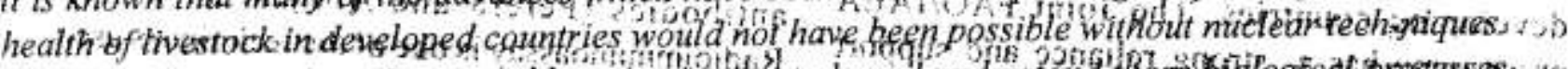

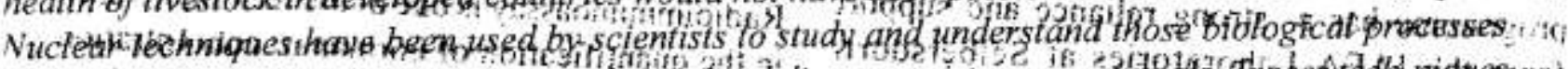

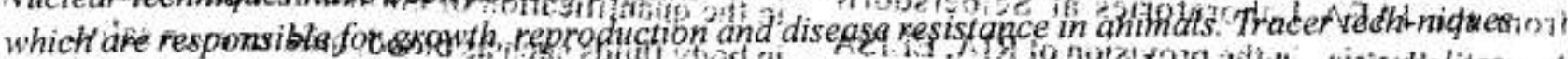

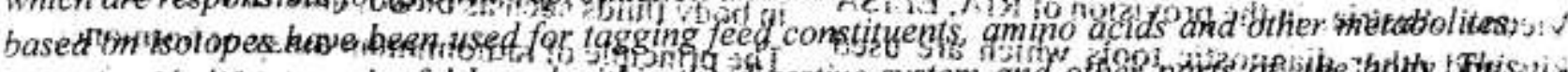

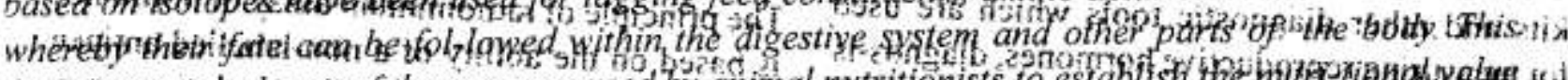

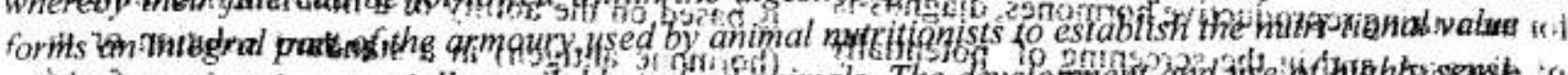

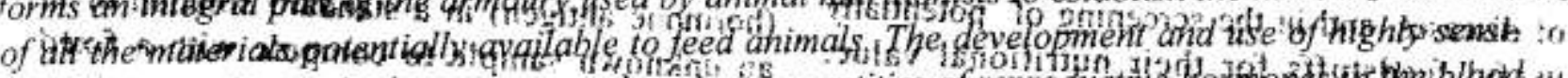

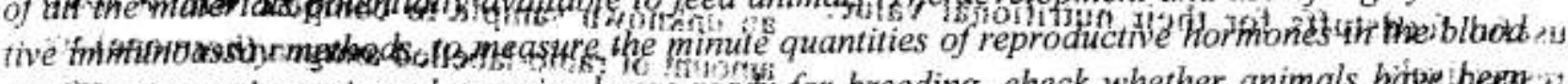

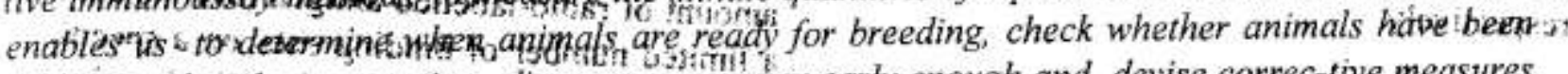

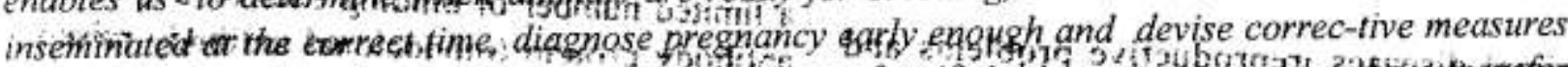

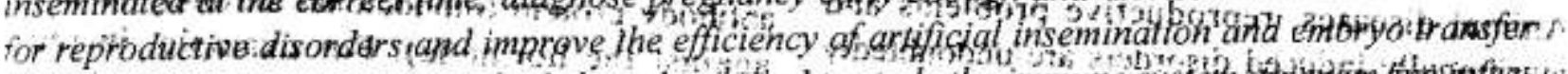

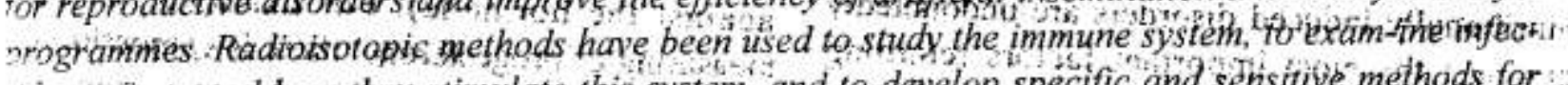
ious agints and how they stimulate this system, and to develop specific and sensitive methods for development of veterinapy vaccines and diagnostic tests

Kexwgrds; Nuclear techniques, RIA, EEISA, nutrition, reproduction; diseases, livestock production

\section{Infroduction}

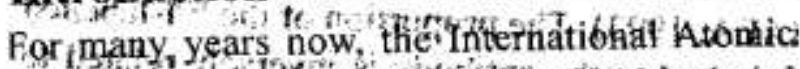
Energy Agency (IAEA) and Food Agrlcular $A$ Qrqanjation (F $\mathrm{AO}$ ) have tun a joint programme tgihelpsome countries develop, test arad rapply

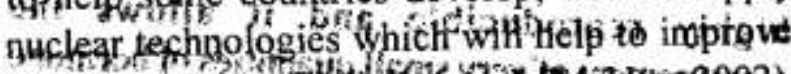

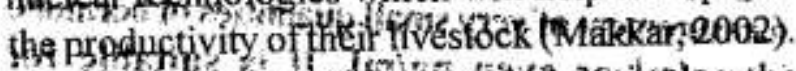
The programme addresses in partikalan the problems of feeding, Bredifib and controbof diseases of animals in some develóloping goountries. It is specifically directed at the siriat farmen who keeps ruminant livestock, i.e. animals which cqnyert grass or other materials containing lignocellulose into meat, woot, trifk; dtaught power $e_{2}$ ts and yhich therefore do fot compét with man for food resources (Dargie, 1989; Jasuraya 2002), It is also a prografinte whioh excourages research; not básit cácademier: tesearch but research which is geared 'rowart's under standing of the indigento is itrestock podpction systems

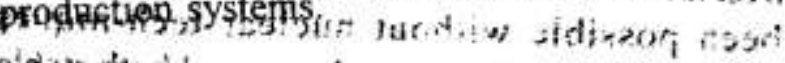
The programme encourages inferdisciphthafy

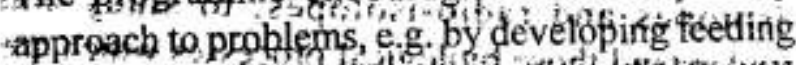
or other management strate gied btich will improve reproductive efficiency, atid to IFS , AY 
complement rather than compete with work of a similar nature being supported by other international or bilateral funding organizations (FAO/IAEA, 1993). A part from its close working relationship with the FAO's Animal Production and Health Division, the Joint FAO/IAEA Division of Nuclear Techniques in Food and Agricuiture, Seiberdorf Laboratories, Vienna, Austria, interacts closely with such organizations as the International Livestock Research Institute (ILRI) in Addis Ababa, the International Laboratory for Research on Animal Diseases (ILRAD) in Nairobi and the International Founda-tion of Science (IFS) in Stockholm as well other funding organizations associated with the Govern-ments of many developed and developing countries. The Joint FAO/IAEA programme has a strong reliance and support from the IAEA Laboratories at Seibersdorf, Vienna, Austria, in the provision of RIA, ELISA kits and other diagnostic tools which are used for measuring reproductive hormones, diagnos-is of diseases, and in the screening of potentially useful feedstuffs for their nutritional value, respectively.

Animal diseases, reproductive problems and nutritionally induced disorders are undoubtedly amongst the most important factors retarding livestock development and hence reducing production of food for human consumption in all parts of the world (IAEA, 1984). There are valuable applications of nuclear and related techniques in the study, diagnosis and in some cases, the control of diseases, reproductive and nutritional disorders of economically important livestock species such as cattle, sheep, goats, pigs, camels etc. The advances which have been made in improving the feeding, fertility and health of livestock in developed countries would not have been possible without nuclear tech-niques (Makkar, 2002). Scientists have used both stable isotopes and radio-isotopes, to study and understand those biological processes which are responsible for growth, reproduction and disease resistance in different types of farm animals (Dargie, 1989).
Principles of nuclear techniques:

\section{Radioimmunoassay (RIA).}

Fifty years ago, hormone conecht at ons in body fluids, such as blood, urine milk were determined by biological and ch mical methods (Edqvist and Stabenfeldt, 1980: Lahlou-Kass: and Lakldissi, 1s. These mehods, however, lacked sensitivity and were poorly reproducible. RIA was deveioped from the studies of diabetic patients; that the plasma of patients receiving insulin could bind insulin labelled with [ $^{131}$ (Yalow and Berson, 1960). The term radioimmunoassay refers specifically to that form of saturation analysis, in which there is competition between material to be measured, and a radioactive substance for binding sites on antibodies (Perera and Abeyratne, 1979). Radioimmunoassay is one of the techniques used in the quantification of hormonal concentration in body fluids such as blood, milk or even saliva. The principle of radioimmunoassay of hormones is based on the ability of a non-labelled antigen (hormone antigen) in a standard solution or in an unknown sample to compete with a fixed amount of radio-labelled antigen (hormone) for a limited number of binding sites on a specific antibody protein (monocional antibody raised against the hormone). For example, in the measuring of progesterone, there is competition between progesterone $\left(P_{4}\right)$ in plasma, serum or milk and ${ }^{125}$-labelled $\mathrm{P}_{4}$ (tracer or buffer) for a limited number of binding sites on a progesterone - specific antibody immobilized (coated) on the internal walls of test tubes i.e. solid phase (FAO/ IAEA, 1993). The proportion of the 1251-labelled $P_{4}$ bound to the antibody is inversely related to the concentration of the $P_{4}$ present in the plasma, serum or milk. The method is very sensitive and highly reproducible and it allows the measurement of very small quantities of hormone in $\mathrm{ng} / \mathrm{ml}$ or even $\mathrm{pg} / \mathrm{ml}$. It is suitable for monitoring hormone secretion of a single animal and usually, $100-200 \mu \mathrm{l}$ of plasma is sufficient for each analysis (Edqvist and Stabenfeidt, 1980). 
Nuclear techniques

Enzyme Linked Immunosorbent Assay (ELISA).

Enzyme linked immunosorbent assay (ELISA) is an assay for the detection or quantification of an antibody (enzyme) using a ligand conjugated to enzyme which changes color of a substrate (Catty and Raykundalia, 1990). In the early 1970 s, the search for simple sensitive methods for detecting and quantifying antigen and antibody that did not rely upon particle agglutination or radio labelled reagents led to the development of solid phase enzyme coupled reagent assays. In principle, the labelling by chemical conjugation of an enzyme to either antigen or antibody allows detection of immune complexes formed on a solid phase, as the fixed enzyme once washed free of excess reagents, and on a subsequent substrate interaction can yield a colored product which can be visualized and or measured by optical density (Catty and Raykundalia, 1990). The approach has many of the properties of an ideal immunoassay; it is versatile, robust, simple to perform, uses stable reagents economically and achieves, by use of the solid phase, a simple separation of bound and free moieties. Because of their combined simplicity and sensitivity, solid phase enzyme immunoassays can be used reliably for the screening of large number of small volume tests samples in the simplest of laboratory environments. This technical advance has had the greatest impact in the epidemiology and in the diagnosis of infectious diseases (Wright et al. 1993). The assays are also used routinely for screening monoclonal antibodies, for the detection and measurement of hormones and drugs, for determination of specific antibody isotopes and immune complexes, and for many other applications (Wright et al. 1993). Problems of specificity can be brought to a minimum by the use of quality-controlled reagents and standardized procedures (FAO / IAEA, 1993). A variety of solid phase surfaces have been exploited; the earliest tests relied on plastic tubes, but these have been largely replaced by plastic microtitration plates with flat, optically clear, well bottoms to allow easy in situ optical density

\section{liyestock production}

measurements with special enzyme - linked immunosorbent assay readers (Wright et al. 1993).

The performance of ELISA and related solid phase assays depends on four major principles (Catty and Raykundalia, 1990): (i) antibody or antigen is chemically coupled to an enzyme, i.e. formation of conjugates. (ii) antibody or antigen is coated onto ELISA plates well i.e. antibody or antigen coating. Once antigens or antibodies applied to coat or "sensitize" the solid phase are bound, they become resistant to vigorous washing in detergent buffer whilst excess unbound reagent is simply removed by this process (iii) formation of one or more layers of immune complex on solid phase i.e. washing steps between the immune complex layers. This affords the basis for a high specific to non-specific signal ratio when captured enzyme reacts with substrate (iv) an enzyme conjugate of antibody or antigen when bound in the immune complex leaves the enzyme component available for substrate interaction. Addition of substrate, in the usual form of assay, results in a progressive substrate solution color change. The reaction can be stopped at an appropriate stage and the color signai determined by visual comparison with standards or by optical density measurement.

\section{Nuclear applications}

\section{Animal mutrition}

The basic reason for the poor performance of livestock in developing countries is the seasonal inadequacy of feed both in quantity and quality (Jasuraya, 2002). Many feed resources that could have a major impact on livestock production continue to be unused, underdeveloped, poorly utilised with little or no feed supplementation, often due to lack of infrastructure, technical know-how and poor management (Dargie, 1989). Forages, tannin-rich feeds, rice straws and cereal crop residue are by far the major sources of roughage available to the farmers to feed their animals (Getachew et al. 1998). The nutritional 
zonstuined by low nitrogen and high fiber contents as they contain large amounts of ignicellulose, and ar: hishty indigestible Jasuraya, 2002i. Th: efficiency of the termentation process witich akes friace in the rumen is responsible for digesting the feed, and can be optimized by providing nut in needed by the rumen bac-teria and protozos, nt this way the grass or straw coutd be more yiickly and easily digested (Smith, 2002), Therefore, supplements with high proportion 'bypass' nutrients or proteins would escaps breakdown in the rumen and be digested in inc animals intestines from where they could then be absorbed and used to produce proteins twitgrow a (Dargi. 1989). To identify supplt...nts with the characteristics, scientists have used rat. labelted materials to measure the efficiency of the rumen fer-mentation procc it an imat, some of the most commonity available products to determine how much protein could avoid rumen breakdown and reach the intestines (IAEA, 1998a).

In vitro rumen fermentation technique can be used for evaluation of nutritional quality of both conventional and non-conventional fecds (Blummel et al. 1997: Getachew et al. 1998). The technique is based on the quantification of substrate degraded or microbial protein produced using internal or external markers, and of gas or short chain fatty acids (SCFA) production in an in vitro rumen fermentation system based on syringes (Menke et al.1979). Thus, during in vitro evaluation of tannin-rich feeds, the microbial protein production can be quantified using diaminopimelic acid or purines as markers, or by isotopes ${ }^{15} \mathrm{~N}^{32} \mathrm{P},{ }^{35} \mathrm{~S}$ incorporated into the microbes and the partitioning factor for tanninrich feeds can be expressed as the microbial mass determined by these markers per $\mathrm{ml}$ of gas, or short chain fatty acids (SCFA) produced (Chen et al, 1990). In the preserice of tanaininactivating agent (polyethylene glycol), tanninrich browse and herbaceous légumes can have their in vitro degradable nitrogen values raised
(Makkar ard Singh, 1.992 ) leading to the availability of nutrients and increased tracrobial protein synthesis which in turn can increase degradability of nutrients leading to better animal perfomane. The technique entables seiection of a ieed for igh efficiency of microbial protein sjnthesis tis ien atong with high dry natter thin thity "This provides a basis for developincit? it feeding strategies to better s.nchromize energy and nutrient release to maximize substrate fixation into rumen nicrobial cells leading to increase in the supply A protein to intestine and reduce methant vitution from ruminants (Menke et al. is 74 ).

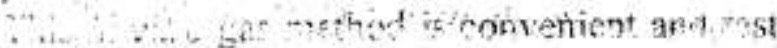
wh allows a larte number of samples to be hiofled at a time.

Nowhic tas the mpact of isofopicmethods heen 30 heavily brought to bear as in the develomment of feeding strategies for farm animals. Tracer tech-niques based on isotopes such as ${ }^{14} \mathrm{C},{ }^{125} \mathrm{l}$, ${ }^{12} \mathrm{P},{ }^{75} \mathrm{~S}^{51} \mathrm{Cr}$ and ${ }^{15} \mathrm{~N}$ have been used for tagging feed constituents, amino acids and other metabolites, whereby their fate can be fol-lowed within the digestive system and other parts of the body (Dargie, 1989; IAEA, 1998a). This forms an integral part of the armoury used by animal nutritionists to establish the nutri-tional value of all the materials potentially available to feed animals as well as the protein, energy and mineral requiremerits of the animals themselves (Chen et al.1990; IAEA, 1998a). Isotopic. methods have therefore been at the centre of developing the modern nutritional concepts which underlie present systems of livestock feeding, increasing not only rates of growth and yieids of milk but also the qual-ity of the meat, milk and other prodúcts (Nákkar, 2002).

\section{Animal Reproduction}

The application of RIA has increased our knowledge of the circulating levels and mote of secretion of most of the reproductive hormones in domestic animals, i.e. those of the hypothalamus, hypophysis, ovary, testis, uterus 


\section{Nuclear technigues in}

hypothalamus, hypophysis, ovary, testis, uterus or placenta (Stabenfeldt et al. 1976; Perera and Abeyratne, 1979; Derivaux and Ectors, 1980; Peters and Ball, 1995). The general study of such hormones like, gonadotrophin - releasing hormones, follicle stimulating hormones, luteinizing hormones, androgens, estrogens, prolactin, prostaglandins, testosterone and progesterone has clarified the fundamental mechanisms which regulate puberty, sexual cycles, gestation, parturition and lactation in the domestic animals (Edqvist et al. 1976; Peters and Ball, 1995). Amongst all these hormones, the profile of progesterone secretion appears to be the most reliable and practical indicator of reproductive function in the female animal (Edqvist et al. 1976; Edqvist and Stabenfeldt, 1980; Adeyemo and Heath, 1980; Lahlou-Kassi and Lakhdissi, 1984; Oyedipe et al. 1988).

In the cow, the progesterone pattern has the following characteristics: elevated plasma concentration of progesterone $(>1 \mathrm{ng} / \mathrm{mL})$ indicates an active corpus luteum and is seen for as long as 12 days during the luteal phase of the oestrous cycle and during the whole period of gestation; while a low plasma progesterone concentrations $(<\mathrm{lng} / \mathrm{mL})$ indicates the absence of an active corpus luteum and is seen in prepubertal animals or in animals that otherwise lack sexual function or are in the follicular phase of the oestrous cycle (Oyedipe et al. 1986; 1988; Peters and Ball, 1995). Thus, two or three consecutive blood or milk progesterone jeterminations, made at weekly intervals, can indicate whether an animal is acyclic, cyclic or pregnant. Radioimmunoassay of $\mathrm{P}_{4}$ in milk or plasma has practical applications in the monitoring of reproductive processes; and information obtained can be used to regulate and control these processes for the improvement of the reproductive efficiency of livestock e.g. induction and synchronization of oestrus in cattle (Lahlou-Kassi and Lakhdissi, 1984; Voh et al. 1987; Rekwot et al. 2000). Progesterone measurements can be used as means of

\section{livestock nroduction}

investigating infertility caused by infections of the genital tract, onset of puberty, and resumption of postpartum ovarian activity, poor oestrus detection, silient oestrus and wrong insemination time (Lahlou-Kassi and Lakhdissi, 1984; Dawuda et al. 1989; Rekwot et al. 2000).

In Morocco, for example, staff at the King Hassan II University in Rabat using hormone and other measurements found that the D'Man breed (local) of sheep cycled throughout the year, while the other local breeds had their ovarian activity shut down for six months of the year, which meant that they could only breed at very restricted times (Dargie, 1989). The implication of these findings is that, with the all year round ovarian cyclicity, the D'man breed had a lambing interval of only six to seven months (compared to the lambing interval of one year of other breeds) and so could easily reach the target of providing three or more crops of lambs every two years.

Determination of $\mathrm{P}_{4}$ in blood and milk on day of insemination and 21-22 days after insemination has practical application of ensuring that not only that animals are being inseminated at the correct stage of their reproductive cycles, but also early pregnancy diagnosis is carried out for future planning (Maurer and Echternkamp, 1985; Dawuda et al. 1988; Rekwot et al. 2000; Galloway et al. 2001). In cattle management, it is economical and profitable to diagnose pregnancy early after insemination so that cows that fail to conceive may be rebred. This early pregnancy test is now available which allows much earlier diagnosis than would be possible by palpating the reproductive organs via the rectum, something which is obviously important from the standpoint of the subsequent management of the cow. RIA for $\mathrm{P}_{4}$ in serum or milk is of practical value in the monitoring of ovarian activity in dairy cattle, since $\mathrm{P}_{4}$ profiles can be used to identify early embryonic mortality, acyclic, 
cyclic cows and repeat breeders (Ayalon, 1978; Oyedipe et al. 1986; Rekwot et al. 2000).

RIA methods in combination with laparoscopy and the collection of data on reproduc-tive and productive indices, have made it possible to unearth many new facts about the unique reproductive physiology and behaviour of both male and female animals and novel methods have been developed or are being researched to manipulate these for better productivity (Dargie, 1989; IAEA, 2001). The application of RIA and related techniques to detect reproductive hormones in blood, milk, saliva and urine has become a powerful tool in investigations designed to improve reproductive function (Perera and Abeyratne, 1979; Edqvist and Stabenfeldt, 1980; IAE $\Lambda, 2001$ ). Such techniques enable reproductive hormone levels in body fluids to be measured down to a concentration of $15 \mathrm{pmol} / \mathrm{L}$. Radioimmunoassay of $\mathrm{P}_{4}$ in milk or serum has been used extensively for investigations of reproductive processes in cattle for many years (Galloway et al. 2001). In developing countries, monitoring of ovarian activity, diagnosing of pregnancy, assessing the accuracy of oestrus detection, surveying the efficiency of artificial insemination services and the studying the effectiveness of the interventions such as feed supplementation are among the recent uses of assaying $\mathrm{P}_{4}$ in milk (IAEA, 1996; 2001).

\section{Animal health}

Nuclear tech-niques play a vital role both directly and indirectly, in the field of animal health and have helped to revolutionize knowledge of how the body reacts to and controls infection. Nuclear tech-niques based on the use of amplifying makers, including radioisotopes, offer great advantages in terms of sensitivity, specificity and reliability (Midgley et al. 1969; FAO/LAEA, 1993). Isotopes such as ${ }^{3} \mathrm{H},{ }^{14} \mathrm{C},{ }^{32} \mathrm{P},{ }^{51} \mathrm{Cr},{ }^{99} \mathrm{~T}{ }_{\mathrm{e}}{ }^{\mathrm{T}}$, ${ }^{75} \mathrm{Se}$ and ${ }^{125} \mathrm{I}$ have been involved in the assessment of biological functions or systems of cellmediated immunocompetence, phagocytosis and cell-mediated cytotoxicity which are used to measure the immune status of any host (Duffus, 1984). Radioisotopic methods have been developed to study the different branches of the immune system, to exam-ine infectious agents and how they stimulate this system, and to develop specific and sensitive methods to determine whether an animal is infected with a particular disease agent, necessary for the development and formulation of many veterinary vaccines and diagnostic tests (Crowder, 1984).

It is known that when animals are given properly prepared vaccine, anti-bodies against the virus or organism start to appear in the blood within one week, and by about three weeks the antibodies have reached a level which is sufficient to protect the animals against the disease for the rest of their lives. Until recently, the best way to detect these antibodies was the virus neutralization test i.e addition of serum from animals to a culture of virus and cells. If the serum contains antibodies, the ability of the virus to invade and destroy the cells is neutral-ized and this can be observed under the microscope. With the introduction of nuclear techniques, it is easier to develop and validate sufficiently sensitive and specific immunoassay methods for diagnosing or monitoring of these diseases so that programmes aimed at their control or eradication can be made more effective and less costly. A lot of research work has been done on the effectiveness of treatment and or vaccination strategies against trypanosomosis, rinderpest, peste des petits ruminants, contagious bovine pleuropneumonia, contagious caprine pleuropneumonia, foot and mouth disease, newcastle disease, gumboro etc using immunoassay-based technologies for increasing animal production (IAEA, 2002).

Nuclear tech-niques have three principal applications in veterinary parasitology: control of infections through the use of vaccines based on radiation-attenuated parasites; use of radoisotopically labelled host cells, parasite 
antigen and antibodies; and the use of in vitro and in vivo labelled parasites in the study of disease process (Duffus, 1984; Holmes, 1984). Nuclear techniques have been used for the diagnosis of trypanosomosis, helminthoses, and tick bome diseases (Katende et al; 1990; Wright et al; 1993). Trypanosomosis, with an outstanding clinical feature of anaemia, is widely recognized as a disease of major importance to both man and animals in the tropics. In Africa alone, around forty countries and 10 million square kilometres of land carrying 150 million cattle are affected in one way or another by the presence of the tsetse flies (Glossina species), which transmit the disease by biting animals and injecting trypanosomes which then proceed to destroy red blood cells and the immune system; causing heavy mortality (Anosa, 1981). Diagnosing trypanosomosis is not easy because infected animals often have so few parasites in the blood that these cannot be found by the microscopy methods; while in serological methods, antibodies present may not necessary indicate a current infection.

To circumvent these problems and also to help decide which of the several species of trypanosomes is responsible for disease in a given location, it is necessary to have a diagnostic test which will pick up and classify the trypanosome in the blood even when the parasites are present in extremely low concentrations (Holmes, 1976). Using ELISA along with polymerase chain reaction (PCR) and other related molecular biotechnologies, many of which require radioisotopes, workers at the International Laboratory for Research on Animal Diseases (ILRAD) in Nairobi succeeded in isolating materials from trypanosomes (antigens) which also appear in the blood of infected animals (Dargie, 1989). They then produced highly specific anti-bodies (called monoclonals) against these antigens and developed immunoassays using these antibodies which could detect the specific trypanosome antigen in very low levels in the blood of infected livestock. The enzyme-linked immunosorbent assay technique is simple, reliable, accurate and serves as a powerful and cheap method of not only to diagnose diseases and thereby establish ffective (Catty and Raykundalia, 1990; Wright et al. 1993). A further advantage of this approach is that because large numbers of samples can be easily analysed, it will be possible to carry out large scale monitoring of diseases in different regions of a country and then to develop contrel strategies which optimize the use of drugs, insecticides or vaccines (Wright et al.1993).

Nuclear techniques have made a major contribution to the understanding of the pathogenesis and immunology of trypanosomosis (Holmes, 1984). Radioisotopic tracer techniques using ${ }^{51} \mathrm{Cr}$-red cells, ${ }^{59} \mathrm{Fe}$-transferrin and ${ }^{125} \mathrm{I}$ albumin have been invaluable tools for examining the underlying mechanisms in trypanosome infected animals, involving the development of techniques for radiolabelleing of trypanosomes and their subsequent uses in the measurements of immune clearance and the evaluation of the factors influencing clearance of parasites from the blood (Dargie, 1975; Holmes, 1976; Anosa, 1981).

Nuclear techniques have been of great value in the application of the sterile - male technique through the use of radiation sources such as gamma radiation and $\mathrm{x}$-rays in the suppression and reduction of tsetesfly population (Curtis, 1973; Langley et al. 1974; NITR, 1984). The xrays destroy certain parts of the reproductive system of the male tsetseflies probably disrupting spermatogenesis, and thereby sterilize them but without really affecting the normal life and the natural behaviour of the flies (Langley et al. 1974; NITR, 1984). The sterilized males are then released back to the fields, and are able to detect and mate the females just as the normal males, but without fertilization (Curtis, 1968; NITR, 1984). 
The use of gamma irradiation to produce stable strains of Babesia. Theileria and Anaplasma species for the production of protective live vaccines has been practised in a number of countries, particularly in Australia and South Africa for many years (Irvin, 1984; Wright, 1984). These strains are produced either by rapid passage through splenectomized calves (Babesia bovis) or by slow passage to intact calves which are splenectomized 1 to 14 weeks later, the next passage strain being derived from the splenectomized carrier ( $B$ bigemina). Some of these parasites have been radiolabelled by using different nucleic acid precursors, particularly ${ }^{3} \mathrm{H}$ hypoxanthine and ${ }^{~} \mathrm{H}$-thymine, to help elucidate cyclic changes occurring during parasite development in the bovine lymphoid cells and in the tick salivary glands (Irvin, 1984). Ionizing radia-tion from ${ }^{60} \mathrm{Co}$ or $\mathrm{X}$-ray sources has been used to produce vaccines (irradiated larvae), which are highly efficacious, safe and cost effective and have been used as commercial vaccines against lungworms in cattle (IAEA, 1981). Nuclear related technologies have been in use for the development of packages for the effective monitoring of veterinary drug residues in livestock and livestock products in developing countries (IAEA, 1998b).

\section{Conclusion}

Nuclear techniques are indeed powerful tools for problem solving in livestock production, and are equally important in developing countries, just as in industrialized countries. Nuclear techniques are to be used by scientists in collaboration with farmers to obtain better insight into local problems and to produce materials or nutritional packages which would help farmers to improve the feeding and management of animals. Nuclear techniques have been in use in the production of attenuated vaccines and development of immunoassays for the diagnosis of animal diseases, diagnosis of early pregnancy and reproductive disorders. Determination of $\mathrm{P}_{4}$ in blood and milk on day of insemination and 2122 days after insemination has practical application of ensuring that the animals are being inseminated when they are actually on heat. Immunoassay-based technologies along with PCR and other related molecular biotechnologies have been used in the assessment of the effectiveness of vaccination and treatment strategies against many viral, bacterial, and parasitic diseases for increasing animal pioduction in Africa.

\section{References}

Adeyemo, $O$ and Heath, E. 1980. Plasma $P_{4}$ concentrations in Bos taurus and Bos indicus heifers. Theriogenology 14: 411-420.

Anosa, V.O. 1981. Applications of radioisotope techniques to the study of trypanosomiasis in domestic ruminants and laboratory animals. Isotopes and Radiation in Parasitology IV. Proceedings of Advisory Group Meeting, Cambridge, IAEA, pp. 53.

Ayalon, N. 1978. A review of embryonic mortality in cattle. Journal of Reproduction and Fertility 54: 483-493.

Blummel, M; Makkar, H.P.S and Becker, $\mathrm{K}$ 1997. In vitro gas production: a technique revisited. Journal Animal Physiology and Nutrition 77: 24-34.

Catty, D., Raykundalia, C. 1990. ELISA and related enzyme immunoassays. ntibodies. Vol.II A practical approach. Ed. D. Catty IRL Press Chapter 4, pp. 97-144.

Chen, X.B; Hovell, F.D.D and Orskov, E.R 1990. Excretion of purine derivatives by ruminants: endogenous excretion differences between cattle and sheep. British Journal Nutrition 63 : 121-129.

Crowther, J.R 1984. Radioimmunoassay and related procedures in diagnosis and study of viral infections of domestic animals. IAEA Proceedings. STI/PUB/675, IAEA, Vienna. pp. 1-10. 
Curtis, C.F. 1968. Radiation sterilization and the effect of multiple mating of females in Glossina austeni. Journal of Insect Physiology 14: 1365-1380.

Curtis, C.F. 1973. The use of simulation in the choice of an optimum radiation dose for control of Glossina morsitans. Computer Models and Application of the Sterile-Male Technique. Proceeding Panel, Vienna, 1971; IAEA, Vienna, pp. 177.

Dawuda, P.M; Eduvie, L.O; Esievo, K.A.N; Molokwu, E.C.I. 1988. The use of RIA technique for early pregnancy diagnosis in Bunaji cows. Proc. 13th Annu. Conf. of Nigerian Society for Animal Production. Calabar, Nigeria pp. 69-77.

Dawuda, P.M; Eduvie, L.O; Esievo, K.A.N; Molokwu, E.C.1. 1989. Silent oestrus manifestation in Nigerian Bunaji Zebu cows. Animal Reproduction Science 21: 79. 85.

Dargie, J.D.1975. In: Animal models in Parasitology. Owen, D (eds.). Macmillan, London, pp. 17.

Dargie. J.D. 1984. Nuclear techniques in the study of genetic resistance of gastrointestinal -ematode infections in sheep. IAEA Pr.cedings. STI/PUB/675, IAEA, Vienna. $2 \div .49$

Dargie. J.D. 1989. Helping small farmers to zerreve their livestock. Joint FAO/LAEA 7. s:on of nuclear techniques in Food and 4 z: :ulrure, IAEA Reprint from IAEA is trock 1989, pp. B35-B55.

Eewex. J and Ectors, F. 1980. 3 -.r.mathologie de la gestation vet acrs?:aue veterinaire, Ed. Du point eezare. Maisons Alfort, pp. 23.
Duffus, W.P.H. 1984. Isotope-based immunological techniques. Their use in assessment of immune competence and the study of immune responses to pathogens. IAFA Proceedings. STI/PUB/675, LAEA, Vienna. pp. 159- 168.

Edqvist, L.E; Haggstrom, A; Kindahl, H; Stabenfeldt, G.H. 1976. Radioisotopic techniques for the study of reproductive physiology in domestic animals. 1. Assay procedures, nuclear techniques in Animal production and Health (Proc. Symp. Vienna, 1976), pp. 513.

Edqvist, L.E and Stabenfeldt, G.H 1980. Reproductive hormones. In: Clinical Biochemistry of Domestic Animals. Academic Press, New York.

FAO/IAEA 1993. The F $\Lambda O /$ LAEA Progesterone RIA Kit manual.

Galloway, D.B; Perera, B.M.A.O and Manar, 2001. A strategy for establishing diagnostic and related services to dairy farmers in developing countries based on RIA of $\mathrm{P}_{4}$ in milk. In: RIA \& related techniques to improve Al programmes for cattle reared under tropical and sub-tropical conditions (Proceedings of a final Research Coordination meeting organized by the Joint FAO/IAEA Division of Nuclear Techniques in Food and Agriculture and held in Uppsala, Sweden). JAEA, TECDOC-1220, IAEA, Vienna, pp.197-207.

Getachew, G; Makkar, H.P.S and Becker, R 1998. The in vitro gas coupled with ammonia nitrogen measurement for evaluation of nitrogen degradability in low quality roughages using incubation medium of different buffering capacity. Journal of Science, Food and Agriculture 77: 87-95. 
Holmes, P.H. 1976. Use of radioisotopic trace techniques in the study of the pathogenesis of trypanosomiasis. Nuclear Techniques in Animal Production and Health. Proc. Symposium Vienna, IAEA, pp 463.

Holmes, P.H. 1984. Nuclear techniques in the study of pathogenesis and immunology of trypanosomiasis. IAEA Proceedings. STI/ PUB/675, LAEA, Vienna. pp.135-148.

IAEA 1981. Isotopes and Radiation in Parasitology IV. Proceedings of Advisory Group Meeting Cambridge, 1979, LAEA, Vienna, Austria.

IAEA 1984. Nuclear techniques in tropical animal diseases and nutritional disorders. IAEA Proceedings. STI/PUB/675, IAEA, Vienna.

IAEA 1996. Development of feed supplementation strategies for improving ruminant productivity on smallholder farms in Latin America through the use of immunoassay techniques, IAEA, TECDOC -877, IAEA, Vienna.

IAEA 1998a. Development, standardization and validation of nuclear-related technologies for measuring microbial protein supply in ruminant livestock for improving productivity. Final Research Co-ordination meeting, 24-28 August, Vienna, Austria. In: Animal Production and Health Newsletter 29: 12-15.

IAEA 1998b. FAO/IAEA Consultant meeting on monitoring of veterinary drugs residues in livestock and livestock products in developing countries. In: Animal Production and Health Newsletter No. 28 , pp. 8
IAEA 2001. Radioimmunoassay and related techniques to improve artificial insemination programmes for cattle reared under tropical and sub-tropical conditions (i) roceedings of a final Research Co-ordination meeting organized by the Joint F.AO/AEA Division of Nuclear Techniques in Food and Agriculture ana held in Uppsala, Swedent. IAEA, TECDOC-1220, LAEA, Venna.

IAEA 2002. Effectiveness of vaccination strategies against livestock diseases. Animal Production and Health Newsletter. No. 28 pp. 15

Irvin, A.D 1984. Nuclear techniques in the study of East Coast Fever (Theileria parva) infection of cattle. IAEA Proceedings. STI PUB/675, IAEA, Vienna. pp. 189- 202.

Jasuraya, M.C.N 2002. Principles of ration formulation for ruminants. In: Development and field evaluation of animal feed supplementation packages. IAEATECDOC-1294, ISSN 1011-4289.pp.9-14.

Katende, J.M; Goddeeris, B.M; Morzaria, S.P and Musoke, A.J 1990. Identification of a Theileria mutans specific antigen for use in an antibody and antigen detection. ELISA. Parasitic Immunology 12: 419-433.

Lahlou-Kassi, A and Lakhdissi, H 1984. RIA techniques and reproductive management of livestock in North Africa. IAEA Proceedings. STI/PUB/675, IAEA, Vienna. pp. $41-56$.

Langley, P.A; Curtis, C.F and Brady, J 1974. The viability, fertility and behaviour of tsetseflies (Glossina morsitans) sterilized by irradiation under various conditions. Entomology, Experimental and Applied 17: 97-111. 
Nuclear techniques in

Makkar, H.P.S 2002. Applications of the in vitro gas method in the evaluation of feed resources and enhancement of nutritional value of tannin-rich tree/browse leaves and agro-industrial by-products. In: Development and field evaluation of animal feed supplementation packages- $\triangle A E A$ TECDOC-1294, ISSN 1011-4289 pp.2340 .

Makkar, H.P.S and Singh, B 1992. Detannification of oak leaves: treatment and their optimization. Animal Feed Science Technology 36: 113-127.

Maurer, R.R and Echternkamp, S.E 1985. Repeat breeder females in beef cattle: influences and causes. Journal of Animal Science 61 (3): 624-636.

Menke, K.H; Raab, L; Salewski, A; Steingass, H; Fritz, D and Schneider, W 1979. The estimation of the digestibility and metabolizable energy content of ruminant feedstuffs from the gas production when they are incubated with rumen liquor in vitro. Journal Agricultural Science (Camb.) 92: 217-222.

Midgley, A.R; Niswender, G. D and Regar, R.W 1969. Principles for the assessment of the reliability of radioimmunoassay methods. Acta Endocrinology 63: Suppl. 142:163.

Nigerian Institute for Trypanosomiasis Research 1984. Nigeria goes nuclear: In war against tsetse flies. Sunday New Nigeria, 11 March, 1984, pp.16.

Oyedipe, E.O; Pathiraja, N; Voh, A.A and Buvanendran, $V$ 1988. Use of plasma $P_{4}$ profiles for the assessment of reproductive functions in indigenous Nigerian Zebu cattle. Theriogenology 30 (3): 629-641.
Oyedipe, E.O; Voh, A.A; Marire B.N and Pathiraja, N 1986. Plasma progesterone concentrations during the oestrous cycle and following fertile and non-fertile inseminations in Zebu heifers. British Veterinary Journal 142:41 - 46.

Perera, B.M.A.C and Abeyratme, A,S 1979. The use of nuclear techniques in improving reproductive performance of farm animals. World Animal Review 32: 2-6.

Peters, A.R and Ball, P.J.H 1995. Pharmacological control of the oestrous cycle. In: Peters, A.R and Ball, P.J.II (eds). Reproduction in cattle. Blackwell Science. 2nd edition, pp. $89-105$.

Perera, B.M.A.C and Abeyratne, A.S 1979. The use of nuclear techniques in improving reproductive performance of farm animals. World Animal Review 32:2-8.

Rekwot, P.I., Ogwu, D; Sekoni V.O and Oyedipe, E.O 2000. Serum progesterone profiles of zebu cows in relationship to conception and repeat breeding after artificial insemination. Animal Reproduction Science 63:41-51.

Smith, T 2002. On-farm treatment of straws and stovers with urea. In: Development and field evaluation of animal feed supplementation packages. IAEA-TECDOC-1294, ISSN 1011-4289. pp.15-22.

Stabenfeldt, G.H; Kindahl, H; Edgvist, L.E 1976. Radioisotope techniques for the study of reproductive physiology in domestic animals. 2. Physiological implications, ibid; pp.525. 
Voh, A.A; Oyedipe E.O; Pathiraja, N; Buvanendran, $V$ and Kumi-Diaka, $J$ 1987. Peripheral plasma levels of progesterone in Nigerian Zebu cows following synchronization of oestrus with prostaglandin $r_{2}$ alpha analogue (dinoprostromethamine). British Veterinay Journal 143: $254-263$.

Wright, I.G 1984. Nuclear techniques in babesiosis and anaplasmosis. IAEA Proceedings. STI/PUB/675, IAEA, Vienna. pp. 169-187.
Wright, P.F; Nilsson, E; Vanrroij, E.M.A 1993. Standardization and validation of enzymelinked immunosorbent assay lechniques for the detection of antibody in infectious diseses diagnosis. Review Science, Technology and Epizootics 12(2): 435-450.

Yalow, R.S and Berson, S. A 1960. Immutivassay of endogenous plasma insulin in man. Journal of Clinical Investigation 39:11571175.

(Received 10 March 2001; Accepted 14 June 2005) 